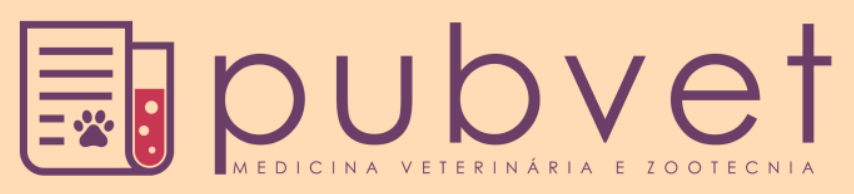

HTTP://DX.DOI.ORG/10.22256/PUBVET.V11N11.1123-1128

\title{
Exames auxiliares como ferramenta no diagnóstico clínico veterinário
}

\section{Luiza da Gama Osório ${ }^{1 *}$, Tatiana de Ávila Antunes², Mariana Sabbado², Luciana Gil ${ }^{3}$, Renata Osório de Faria $^{4}$, Marlete Brum Cleff ${ }^{5}$, Carmem Lúcia Ribeiro ${ }^{5}$, Ana Raquel Mano Meinerz ${ }^{5}$}

\author{
${ }^{1}$ Pós-Doutorado PNPD-CAPES Programa de Pós-Graduação em Veterinária-Universidade Federal de Pelotas, Brasil. \\ ${ }^{2}$ Médica Veterinária. \\ ${ }^{3}$ Bioquímica do Laboratório de Análises Clínicas-Universidade Federal de Pelotas, Brasil. \\ ${ }^{4}$ Professor Adjunto do Departamento de Veterinária Preventiva-Universidade Federal de Pelotas, Brasil. \\ ${ }^{5}$ Professor Adjunto do Departamento de Clínicas Veterinária-Universidade Federal de Pelotas, Brasil. \\ *Autor para correspondência, E-mail: luizaosorio@yahoo.com
}

\begin{abstract}
RESUMO. Considerando a relevância das análises clínicas no estabelecimento e auxilio ao diagnóstico clínico veterinário, o texto traz uma análise da relação entre laboratório e veterinário, e como ambos devem proceder para alcançarem seus reais objetivos de facilitadores no diagnóstico clínico. Nesse contexto ressalta-se as análises clínicas como adjuvantes em diferentes situações patológicas, além de enfatizar o papel fundamental do clínico veterinário como colaborador para que essas análises sirvam de auxilio na sua rotina clínica.
\end{abstract}

Palavras chave: Análises, patologia clínica, animal

\section{Auxiliary exams such as clinical veterinary}

ABSTRACT. Considering the importance of medical tests and assistance in establishing the diagnosis veterinary practitioner, the text provides analysis of the relation between laboratory and veterinary use and how boths hould proceed toachieve their real goals of facilitators in the clinical diagnosis. In this context, it is high the fact that the clinical analysis complements in different pathological situations, and emphasizes the role of the veterinary practitioner as a contributor to these tests serve as an aid in their clinical routine.

Keywords: Analysis, clinical pathology, animal

\section{Exámenes auxiliares en el diagnóstico clínico veterinario}

RESUMEN. Considerando la relevancia de los análisis clínicos en el establecimiento y auxilio al diagnóstico clínico veterinario, el texto trae un análisis de esa relación entre laboratorio y veterinario y cómo ambos deben proceder para alcanzar sus reales objetivos de facilitadores en el diagnóstico clínico. En este contexto se están resaltando análisis clínicos como adyuvantes en diferentes situaciones patológicas, además de enfatizar el papel fundamental del clínico veterinario como colaborador para que esos análisis sirvan de auxilio en su rutina clínica.

Palabras chave: Diagnóstico, análisis, patología, animal

\section{Introdução}

Cada vez mais os animais de companhia, especialmente cães e gatos, são considerados como verdadeiros membros da família. Ao longo de sua evolução, eles tornaram-se mais sociais, estabelecendo laços afetivos mais depurados com 
os seres humanos, auxiliando inclusive na manutenção da saúde mental de seus tutores. Porém, o antropomorfismo exagerado pode causar transtornos aos animais (Tatibana and Costa-Val, 2009).

Essa tendência mundial gerou alterações no comportamento dos cães e gatos, desencadeando enfermidades resultantes principalmente dos hábitos familiares, que são compartilhados por esses pets. A necessidade de alimentos mais palatáveis, petiscos e suplementos, somados ao desequilíbrio entre ingesta e gasto energético são fatores primordiais na perda da autorregulação nutricional dos animais. Vida sedentária, com aumento de peso, redução de atividade física, aumento de estresse psicológico e aumento de sobrevida, predispõe quadros patológicos como obesidade, diabetes e cálculos urinários, entre outros (Pöppl and González, 2005; Guimarães and Tudury, 2006).

Outro aspecto importante que deve ser destacado é a maior sobrevida dos pets, com frequentes diagnósticos de processos tumorais, cataratas, cardiopatias e demais enfermidades relacionadas ao envelhecimento dos animais (Nelson and Couto, 2015).

A isso soma-se o aumento paralelo de áreas relacionadas à nutrição e estética animal, tornando o mercado pet em ascensão, com crescentes expectativas econômicas. Salientando ainda o acréscimo desse mercado, que apresenta grande destaque mundial, sendo um importante e lucrativo segmento da economia (Afonso et al., 2008).

Frente a essa nova realidade crescem também as exigências de todos os profissionais envolvidos nesse contexto, ressaltando a área de Medicina Veterinária, em que os profissionais terão que se reciclar frente a essas exigências, considerando avanços clínico-cirúrgico, terapêutico e de meios auxiliares de diagnóstico. Portanto, entender o papel do animal no grupo social humano a que pertence é essencial para o trabalho do médico veterinário (Tatibana and Costa-Val, 2009).

Muito se fala em programas de qualidade de produtos ou serviços prestados e na importância de se adequar aos anseios dos clientes, o que se aplica aos serviços de saúde. O aumento da complexidade desses serviços impulsionado pelo aumento do mercado, demanda tecnológica, expansão do conhecimento, aumento da expectativa de vida, e de sobrevida de pacientes doenças crônicas, faz crescer a demanda por serviços de saúde com qualidade. Acompanhando esse aumento de demanda em medicina humana, está a medicina veterinária, na busca por programas de qualidade, que se resumem a atendimento humanizado, com alta produtividade e baixo custo (Vieira et al., 2011).

Nessa perspectiva, dá-se ênfase para os meios auxiliares como forma de colaborar com o diagnóstico clínico veterinário. Ressaltando a recíproca, de que as informações passadas pelos clínicos, bem como seu feedback, são extremamente importantes para a qualidade dos laudos nas análises clínicas.

\section{Desenvolvimento}

A comunidade acadêmica em sua totalidade concorda que a clínica é soberana, mas também há de se concordar que nem sempre a clínica oferece todos os subsídios para desvendar a etiologia do quadro, o que é fundamental para o tratamento específico. Dessa forma torna-se claro o quanto os exames auxiliares podem realmente colaborar, ou mesmo estabelecer o diagnóstico de uma determinada patologia. Ainda salientando a importância da utilização desses meios no acompanhamento de protocolos terapêuticos e acompanhamento clínico, sendo inclusive critério para a realização de procedimentos que vão desde transfusões sanguíneas até cirurgias (Meyer et al., 1992; Nelson and Couto, 2015; Prado et al., 2016).

Segundo Gozález e Scheffer (2003), a composição bioquímica do plasma sanguíneo reflete a situação metabólica dos tecidos, auxiliando na avaliação do seu funcionamento, situação nutricional e fisiológica, e na presença de lesões e desequilíbrios metabólicos. Exemplificando, um quadro bastante comum em clínica de pequenos animais, como o de um cão com suspeita clínica de diabete, onde a principal queixa do proprietário é a de que seu animal apresenta poliúria, polifagia e polidipsia. Tríade, esta, comumente associada à patologia, mas que muitas vezes não é observada, mesmo em animais diabéticos (Pöppl and González, 2005). Nesse caso, exames de hemograma e urinálise resultando em achados sugestivos da enfermidade como glicemia elevada e glicosúria, além da presença de corpos cetônicos conduzem o diagnóstico. Em se tratando desse caso, os exames laboratoriais também serão utilizados para o controle da enfermidade, possibilitando uma maior sobrevida com melhor qualidade de vida para o animal 
(Gozález and Scheffer, 2003; Pöppl and González, 2005, Feldman et al., 2014).

Outro exemplo bem ocorrente em clínica de pequenos animais são as infecções do trato urinário, especialmente a cistite, onde a observação de leucocitose com neutrofilia de segmentados com desvio à esquerda, é indicativo de leucograma inflamatório. Associando este exame aos dados fornecidos pela urinálise, com depiúria, bacteriúria, $\mathrm{pH}$ alcalino e odor amoniacal consegue-se determinar que provavelmente tratase de um processo inflamatório de origem bacteriana. Nesse caso a coleta da amostra de urina para cultura e identificação da espécie bacteriana além de antibiograma fornece ao veterinário mais do que o encerramento do diagnóstico, mas também as bases terapêuticas para o caso. O que é de extrema importância, uma vez que a cistite bacteriana é a principal doença do trato urinário inferior de cães e gatos domésticos (Lulich et al., 2008; Chew et al., 2011).

$\mathrm{Na}$ insuficiência hepática crônica, quadro também não raro de ocorrer na clínica de animais de companhia, exames físicos, com observação de mucosas ictéricas e abdome pendular com histórico de vômitos frequentes fazem pensar presuntivamente nessa patologia (Brunetto et al., 2007). No entanto é essencial avaliar enzimas hepáticas, pois seu aumento pode presumir injúria hepática. Assim, pode-se concluir através de exames de coagulação como TSMO (Tempo de sangramento da Mucosa Oral) e TP (Tempo de Protrombina), que a hepatopatia está comprometendo a capacidade de síntese proteica do órgão, a ponto de afetar a cascata de coagulação (Nelson and Couto, 2015).

Em sintomatologia inespecífica, onde é observado através do exame físico desidratação e histórico de apatia, situação em que o clínico não ter, sequer, suspeita clínica, nos exames complementares como hemograma e urinálise é possível verificar alterações bastante sugestivas de determinadas patologias (González and Scheffer, 2003; Nelson and Couto, 2015). Como na observação de alteração na densidade urinária, no caso da isostenúria, sugerindo uma insuficiência renal, que pode ser confirmada pela análise da função renal através da mensuração da ureia e creatinina (Lustoza e Kogika, 2003).

Ou mesmo quando se quer traçar o prognóstico de uma enfermidade ou quadro patológico, como nos casos de fraturas, em que um hemograma pode demonstrar um perfil inflamatório agudo nas primeiras horas após a coleta de sangue, com elevação de fibrinogênio, além de leucograma típico de derrame de corticóide endógeno com leucocitose por neutrofilia e linfopenia, sugerindo a presença de um quadro estressante concomitante à patologia. No decorrer do processo espera-se a normalização dos índices leucocitários, como no leucograma de estresse, normalmente temporário. De forma que a ocorrência de desvio à esquerda e monocitose acompanhado de leucocitose pode predizer uma possível infecção, o que é vital que seja declarado em processos traumáticos, para realização das medidas terapêuticas adequadas a fim de que o quadro não avance (Meyer et al., 1992; Nelson and Couto, 2015).

A principal causa para atendimento de emergência de cães e gatos em hospitais veterinários é o trauma, por acidente automobilístico, briga e queda, respectivamente (Gonçalves, 2015). Segundo Rabelo (2012), saber o número de hemácias do paciente, seu volume globular, ou hematócrito, e o valor da hemoglobina, é de grande importância, por permitir, entre outros fatores, avaliar a capacidade de transporte de oxigênio e outros gases, bem como o volume sanguíneo do paciente. Em relação à bioquímica sanguínea, em uma sala de urgência, é importante relacionar proteínas séricas e plasmáticas, glicose, enzimas hepáticas, ureia, creatinina e eletrólitos.

O trauma compromete funções fisiológicas, imunológicas e metabólicas. Portanto, pensando ainda no caso supracitado de fratura, ao realizar o acompanhamento da evolução clínica de um processo traumático, através do eritrograma, espera-se, devido ao trauma com posterior perda de sangue, uma baixa na série vermelha, indicando anemia, que inicialmente pode apresentar-se sem sinais de regeneração medular, mas com a recuperação clínica do animal pode-se observar anisiocitose e policromasia no esfregaço, sugerindo um processo de regeneração, além da recuperação da massa eritrocitária (Nelson and Couto, 2015). A análise da morfologia dos eritrócitos fornece um auxílio importante no estabelecimento do diagnóstico sobre a causa da anemia. E muitas vezes é também útil no diagnóstico de outras disfunções. (Thrall et al., 2015; Prado et al., 2016). Em relação ao perfil bioquímico, haverá redução da albumina e aumento da bilirrubina, devido à hemorragia, podendo apresentar aumento da ureia em choque hipovolêmico, e aumento da creatinina, pelo dano muscular. Esta elevação de determinadas enzimas 
hepáticas não se justificaria com o decorrer do processo de recuperação do animal, a não ser que este apresente, paralelamente, hepatopatia (González and Scheffer, 2003; Prado et al., 2016).

Os exames auxiliares também servem de diagnóstico, especialmente nos casos de hemoparasitoses e leucemias, em que muitas vezes o animal demonstra sintomas inespecíficos e são os exames laboratoriais que vão definir o diagnóstico. Cabe salientar aqui, também os animais que submetidos a protocolo quimioterápico, em que contagem de plaquetas e leucócitos são limitantes para prosseguir o tratamento. Esses exames aliados a análise da função hepática e renal, órgãos normalmente envolvidos com o metabolismo e excreção dos fármacos, são fundamentais para acompanhamento e controle dos protocolos antineoplásicos (Andrade, 2002; Jericó et al., 2015; Nelson and Couto, 2015).

Até este ponto, foram estabelecidas algumas dentre as inúmeras possibilidades de uso dos exames auxiliares em diversas situações clínicas. No entanto, se os profissionais da área não agirem de forma criteriosa desde a requisição dos exames e armazenamento correto das amostras biológicas, todo o processo evolutivo desse contexto se depara com erros que culminam em resposta também erradas, não cumprindo seu objetivo inicial de auxiliar o diagnóstico clínico (Thrall et al., 2015).

Enfatizando primeiramente a importância da requisição, ela fornece as primeiras observações do clínico para o analista. Quanto mais completa essa estiver, consequentemente haverá mais informações para o analista associar com as possíveis alterações (Thrall et al., 2015). Assim, se torna fundamental que o clínico coloque como observação se foi uma coleta estressante, relembrando do típico leucograma de estresse, especialmente em felinos ou raças de cães mais vulneráveis às mudanças ambientais (Nelson and Couto, 2015). Especificar quantas horas o animal fez a última refeição antes da coleta, com o risco de ocorrer a lipemia levando alterações plasmáticas e sanguíneas sugestivas até mesmo de um quadro de pancreatite aguda, onde a lipemia é frequente (González and Scheffer, 2003).

$\mathrm{O}$ veterinário deverá incluir na sua requisição, os fármacos que estão sendo administrados ao animal. Lembrando que os corticoides tendem a mobilizar leucócitos da camada marginal do endotélio vascular para o circulante, além de aumentar a meia-vida dessas células na corrente sanguínea causando uma leucocitose. Além de reduzir a fase de mitose dos linfócitos e promover a lise dessas células que são sensíveis aos corticóides culminando com uma linfopenia (Prado et al., 2016; Spinosa et al., 2017).

A suspeita clínica deve ser sempre mencionada pelo veterinário requisitante. Caso seja uma suspeita de cinomose, o analista certamente vai processar de forma diferenciada essa amostra, analisando a capa de leucócitos, procurando através das análises microscópicas os corpúsculos de Lentz, estruturas essas patognomônicas para cinomose (Nelson and Couto, 2015).

Da mesma forma que a requisição é fundamental para o andamento de todo o processo, a coleta não é menos importante. Frequentemente o manejo incorreto do veterinário na hora da coleta de sangue pode provocar alterações na amostra, especialmente hemólise. Esta alteração também ocorre em situações de homogeneização violenta do tubo com a amostra e de não retirada da agulha da seringa antes de remover a amostra de sangue para o tubo, bem como o tempo decorrido até o processamento e congelamento da amostra, também são procedimentos frequentemente associados com hemólise. Salientando que estas situações podem sugestionar um quadro anêmico, pela redução do hematócrito, de desidratação, devido ao aumento das Proteínas Plasmáticas Totais (PPTs), ou ainda de disfunção hepática, pelo aumento da AST e ALT, o que pode invariavelmente confundir o raciocínio clínico do veterinário requisitante (Prado et al., 2016).

De igual importância é o entendimento por parte do veterinário que se trata de materiais biológicos sujeitos à ação de microrganismos, lise celular entre outras alterações morfológicas que certamente vão comprometer o diagnóstico. Dessa forma, o tempo que leva do processamento à coleta deve ser respeitado conforme a amostra coletada (Thrall et al., 2015). Por exemplo, o sangue a partir das três horas pós-coleta já inicia processo de hemólise com alterações morfológicas, assim o hemograma deve ser realizado de preferência imediatamente e se não é possível às amostras devem ser refrigeradas por até 24 horas. As amostras de urina, por sua vez são muito sensíveis à ação bacteriana, sendo que em 30 minutos já há alterações na urinálise decorrente da ação de microrganismos, assim deve-se processa-la imediatamente e quando refrigerada 
não ultrapassar a período superior de 12 horas da hora da coleta (Cézar, 2016; Prado, 2016).

\section{Considerações finais}

Considerando todos os fatores descritos com relação ao uso das análises clínicas como auxilio ao diagnóstico para o clínico veterinário, além de como o veterinário deve proceder com as amostras biológicas a serem enviadas para análise, fica claro que as análises clínicas em todo o seu contexto é dependente da conduta do clínico veterinário assim como do analista envolvido, e que ambos se complementam no mesmo sentido de servir como diagnóstico auxiliar ao veterinário e obviamente melhorar o prognostico do animal.

\section{Referências bibliográficas}

Afonso, T., Berdasco, L., Medeiros, T. \& Rejowski, M. 2008. Mercado pet em ascensão - hotelaria para cães e gatos em São Paulo. Revista Brasileira de Pesquisa em Turismo. 2, 102-103.

Andrade, S. F. 2002. Manual de terapêutica veterinária. 2a. ed., São Paulo: Roca Ltda, p. 289-291.

Brunetto, M. A., Teshima, E., Nogueira, S. P., Jeremias, J. T. \& Carciofi, A. C. 2007. Manejo nutricional nas doenças hepáticas. Acta Scientiae Veterinariae. 35, 233-235.

Cézar, F. M. 2016. Controle de qualidade laboratorial: uma atualização em urinálise. Universidade Federal do Paraná. 29p.

Chew, D. J., Dibartola, S. P. \& Schenck, P. A. 2011. Canine and Feline Nephrology and Urology. Elsevier Saunders.

Feldman, E. C., Nelson, R. W., Reusch, C. \& Scott-Moncrieff, J. C. 2014. Canine and feline endocrinology. Elsevier Health Sciences, Philadelphia.

Gonçalves, L. A. 2015. Medicina veterinária de emergência e cuidados críticos: estudo epidemiológico de emergências em uma população hospitalar e uso da avaliação ultrassonográfica torácica focada no trauma (tfast) na triagem do paciente traumatizado. Universidade de Cuiabá - UNIC. 77p.

González, F. H. \& Scheffer, J. F. S. 2003. Perfil sanguíneo: ferramenta de análise clínica, metabólica e nutricional. Anais do I Simpósio de Patologia Clínica Veterinária da Região Sul do Brasil. Porto Alegre: Gráfica da
Universidade Federal do Rio Grande do Sul. p. 73-89.

Guimarães, A. L. N. \& Tudury, E. A. 2006. Etiologias, consequências e tratamentos de obesidades em cães e gatos - revisão. Veterinária Notícias, Uberlândia, 12, 29-41.

Jericó, M. M., Andrade Neto, J. P., Kogika, M. M. 2015. Tratado de Medicina Interna de Cães e Gatos. Ed. Guanabara Koogan LTDA.

Lulich, J. P., Osborne, C. A., Bartges, J. W. \& Lekcharoensuk, C. 2008. Distúrbios do trato urinário inferior dos caninos. In: ETTINGER, S. J., Feldman, E. C. Tratado de Medicina Interna Veterinária. $5^{\mathrm{a}}$ ed, vol. 2, São Paulo: Manole, p. 1841-1867.

Lustoza, M. D. \& Kogika, M. M. 2003. Tratamento da insuficiência renal crônica em cães e gatos. Revista Brasileira de Medicina Veterinária - Pequenos Animais e Animais de Estimação. 1, 62-69.

Meyer, D. J. C., Rich, E. H., Meyer, L. J. D. J., Coles, E. H. \& Rich, L. J. 1992. Veterinary laboratory medicine: interpretation and diagnosis.

Nelson, R. W. \& Couto, C. G. 2015. Medicina interna de pequenos animais. Elsevier Editora, Amsterdan.

Pöppl, A. G. \& González, F. H. D. 2005. Aspectos epidemiológicos e clínico-laboratoriais da Diabetes Mellitus em cães. Acta Scientiae Veterinaria, 33, 33-40

Prado, R. R., Mendonça, E. P., Monteiro, G. P., Melo, R. T. \& Rossi, D. A. 2016. Eritrograma em Medicina Veterinária: Apostila. Pubvet Publicações em Medicina Veterinária $e$ Zootecnia, 10, 61-82.

Rabelo, R. C. 2012. Emergências de pequenos animais: condutas clínicas e cirúrgicas no paciente grave. Elsevier.

Spinosa, H. S., Górniak, S. L. \& Bernardi, M. M. 2017. Farmacologia Aplicada à Medicina Veterinária. Ed. Guanabara Koogan LTDA.

Tatibana, L. S. \& Costa-Val, A. P. 2009. Relação homem-animal de conpanhia e o papel do médico veterinário. Revista Veterinária $e$ Zootecnia em Minas. Ano XVIII, 103, 12-18.

Thrall, M. N., Weiser, G., Allison, R. W. \& Campbell, T. W. 2015. Hematologia $e$ Bioquímica Clínica Veterinária. Ed. Roca Ltda. 
Vieira, K. F., Shitara, E. S., Mendes, M. E. \& Sumita, N. M. 2001. A utilidade dos indicadores da qualidade no gerenciamento de laboratórios clínicos. Jornal Brasileiro de Patologia e Medicina Laboratoria. 47, 201210.
Article History:

Received 5May 2017

Accepted 7 August 2017

Available on line 7 September 2017

License information: This is an open-access article distributed under the terms of the Creative Commons Attribution License 4.0, which permits unrestricted use, distribution, and reproduction in any medium, provided the original work is properly cited. 